\title{
Polychlorinated biphenyl congeners (PCBs) in nursing primiparous and multiparous women
}

\author{
Sobia Khwaja ${ }^{1 *}$, Rubina Mushtaq ${ }^{1}$, Rehana Mushtaq ${ }^{1}$, Masarrat J. Yousuf ${ }^{2}$, Fozia Tabbassum ${ }^{2}$ \\ ${ }^{1}$ Department of Zoology, Federal Urdu University of Arts, Science and Technology, Karachi, Pakistan \\ ${ }^{2}$ Department of Zoology, University of Karachi, Karachi, Pakistan \\ Email: "gr8_dezirez@hotmail.com, wsobia_1988@hotmail.com
}

Received 17 June 2013; revised 30 July 2013; accepted 15 August 2013

Copyright (C) 2013 Sobia Khwaja et al. This is an open access article distributed under the Creative Commons Attribution License, which permits unrestricted use, distribution, and reproduction in any medium, provided the original work is properly cited.

\begin{abstract}
Impact of PCBs was studied as a major source of physiological effects even very low concentration of PCBs transferred to the infants by mother's milk. Milk samples were collected from primipara and multipara women. A significant variation pattern was observed in the level of PCB congeners, as PCBs are lipophilic in nature, another possibility arises that great deals of residues are passed on to infants through mother's milk. A technique was developed to find out polychlorinated biphenyls (PCB) in breast milk. PCBs were extracted by Matrix Solid-Phase Dispersion (MSPD) and analyzed by Gas Chromatography with Electron Capture Detector. The precision $(\mathrm{RSD}<10 \%, \mathrm{n}=125)$, recovery $(85 \%$ to $110 \%)$ and limit of quantification (between 0.50 and 3.00 $\mu \mathrm{g} \cdot \mathrm{L}^{-1}$ ), the chi square analysis at $\mathrm{p} \leq \mathbf{0 . 0 5}$ has shown that the PCB level was higher in multipara as compared to primipara. The analysis of the thirty samples revealed PCB levels above $6.85 \mu \mathrm{g} \cdot \mathrm{L}^{-1}$ in breast milk samples by analyses of a mixture of PCB congeners. All PCB congeners $(28,52,101,123(+149), 118,114$, 153, 105, 138 (+163), 167, $156(+171), 157,180,170$, 189) were found at high level in primiparous and multiparous. Thus, a high correlation between the contamination of breast milk and environmental pollution of PCBs was observed.
\end{abstract}

Keywords: Poly Chlorinated Biphenyls; Primipara; Multipara; Breast Milk; Contamination; MSPD and ECD; Pakistan

\section{INTRODUCTION}

The physiological impact of polychlorinated biphenyls (PCBs) has been studied in humans and in animals. The

"Corresponding author. prime focus in human studies has been on the effects in neonates, women and infants whereas research has also done on adults. According to the National Health and Nutrition Examination Survey (NHANES) concentration of PCBs was examined in serum and lipid content of people who were above twelve years of age.

Polychlorinated biphenyls (PCBs) are lipophilic substance. Humans are exposed to these persistent compounds from different sources. PCBs have been banned for 30 years, but are still found in telephone as dielectrics and pole mounted transformers. Exposure pathways for PCBs, as with most persistent organic pollutants, begin in the outdoor environment [1]. PCBs are characterized by its capacity for bio-accumulation, toxic effects and long distance atmospheric transport. Therefore, they were also present in those places where they have not been used [2], and a number of PCBs congeners have been determined in milk samples [3]. Acute prenatal exposure of PCBs resulted in intrauterine growth retardation, reduced birth weight, delayed developmental milestones, and other abnormalities in infants and children [4,5]. A serious impact of PCBs exposure on human neurodevelopment has been observed [6].

In humans, serum levels of PCBs caused increase in several inflammatory diseases such as infection, sepsis, septic shock and many others [7]. In the similar manner the PCBs are deposited in mother's milk and transferred to their young children. It indicates that the new born may receive the PCB concentration ratio at a greater level as compared to fish and other food items [8].

The current state of knowledge suggests that low-level exposures to PCBs are unlikely to cause any adverse health effects. People at greater risk include Aboriginal peoples, as well as anglers and hunters and their families with the fact that not all of the 209 kinds of PCB have the same effects [9].

Although their use has been restricted in Pakistan decades ago, but PCBs lipophilic nature, these toxic and 
hazards chemicals easily entered into the food chain. As a result mean concentration has been reported in food, blood human tissues and breast milk [10-12]. Recent research in Pakistan has given due importance on the examination and quantity of climatic conditions in major cities populations for determination of impact of industrial pollution.

In Pakistan such studies are scanty and no comprehensive study was conducted therefore the reliable data is not normally available to carry out environmental health and risk assessment. In this study, the residues of PCB were analyzed in women milk samples which were collected through women populace of Karachi. Our object was to measure the concentration level of PCB residues in lactating women those who are indirectly exposed from these organic compounds. Present investigation will provide useful data for upcoming researchers. Wide research has been done globally but in Pakistan no studies have been carried out to create awareness in the society. The usages of PCBs are banned but present findings significantly show that these toxic compounds are still in practice illegally.

\section{Objective}

To assess level of Polychlorinatedbiphenyl (PCBs) and their effects transferred to infants through mother milk were studied associations with their health hazards. This type of study has never done in Pakistan previously. This integration of data from different sources with a mathematical model allows us to assess infant's disease levels, immunological effects and overall uncertainty in predicted risks. The uncertainties resulting from the assessments of exposure and pollution status of PCBs are propagated through the risk characterization process.

\section{MATERIALS AND METHODS}

\subsection{Study Population and Sampling}

\subsubsection{Milk Donors}

The pregnant women who came to register their names for delivery in Karachi Gynae hospitals were divided into two groups multiparous and primiparous. They had been asked about their consent for the milk sample collection. They had been provided a questionnaire for this purpose. After a brief history taken from these women they were followed for their expected days of delivery. They usually showed hesitation in providing the milk sample but the staff nurse helped in this purpose. The breast pump had been provided to the women and lady nurse collected their samples in sterilized vials of $10 \mathrm{ml}$.

\subsubsection{Analytical Method}

Breast milk samples were brought to lab and stored at $-30^{\circ} \mathrm{C}$ till further analysis.

\section{1) Extraction}

Milk sample was extracted through matrix solid-phase dispersion (MSPD) in manifold assembly. The 1-mL breast milk sample was pipette into atared $10-\mathrm{mL}$ conical centrifuge tube and the weight was recorded. The sample was spiked with labeled internal standard to give a concentration of $200 \mathrm{pg} / \mathrm{g}$ in the milk and mixed allowing enough time for the internal standards to reach equilibrium with the milk components [13].

2) Instrumentation

Analyses were performed by gas chromatography using Perkin Elmer GC-Calrus 500. The standard PCB congeners were purchased from Supelco Company. This standard mixture of PCB was injected into GC (ECD) to get the standard mixture peaks for comparison. Concentration level of PCBs were determined analyzed using Perkin Elmner Gas chromatograph Clarus 500 equipped with electron capture detector $(\mathrm{ECD}), 300^{\circ} \mathrm{C}$, mode: constant column + makeup flow, combined flow: $60 \mathrm{ml} / \mathrm{min}$, make up gas type: nitrogen; inlet: operated in split less mode, initial temp: $200^{\circ} \mathrm{C}$, pressure: 17.38 psi, purge flow: $15 \mathrm{ml} / \mathrm{min}$, total flow: $19.2 \mathrm{ml} / \mathrm{min}$; Oven: initial temp: $100^{\circ} \mathrm{C}$, hold time: $5 \mathrm{~min}$, ramp at $4.0^{\circ} \mathrm{C} / \mathrm{min}$ to $220^{\circ} \mathrm{C}$, two capillary columns were used for initial injections (calculations) and for confirmation injections (validate initial injection of pesticides).

a) Initial injections: RTX5 w/Integra Guard, $30 \mathrm{~m} \times$ $0.25 \mathrm{~mm} \times 250 \mu \mathrm{m}$ ID $\times 0.25 \mu \mathrm{m}$ film thickness, constant pressure@17.38 psi, nominal initial flow: 33 $\mathrm{cm} / \mathrm{sec}$.

b) Confirmation injection: RTX35 w/Integra Guard, $30 \mathrm{~m} \times 0.25 \mathrm{~mm} \times 250 \mu \mathrm{m}$ ID $\times 0.25 \mu \mathrm{m}$ film thickness constant pressure@17.38 psi, nominal initial flow: 33 $\mathrm{cm} / \mathrm{sec}$.

It is general practice in pesticide Labs. of CES to use different chromatographic columns for quality assurance. As far as the procedure was carried out for each batch of 6 samples calibration and its authenticity were regularly observed during the start and end. To check the quality control methods the use of reagent blanks surrogate and matrix spike recovery was taken into consideration. For each sample batch there was one procedural blank, one laboratory control sample and a duplicate of sample.The procedural blank was spiked with the solvent and a surrogate internal standard PCBs congeners 198 and 194. All samples were spiked with the surrogate compound to determine efficiency. Results are calculated on the basis of the mean value of samples. Internal spiking and reagent blank determined the recovery values. The recovery values were in the range $92 \%-157 \%$ for PCBs. The limit of quantification was calculated on the basis of $\%$ RSD and it was $0.001-0.01 \mu \mathrm{g} / \mu \mathrm{l}$ and limit of reportable amount was obtained by multiplying with 3 and it was $0.003 \mu \mathrm{g} / \mu \mathrm{l}$ or $0.3 \mathrm{ng} / \mu 1 \mathrm{PCB}$ congeners. 
3) Statistical Analyses

A descriptive analysis was conducted for all PCBs. Arithmetic means and standard deviation (SD) were calculated for normally distributed variables while geometric means and $95 \%$ confidence interval are presented for $\log$ transformed variables. The chi square test was applied for comparison between primipara and multipara women. A $p<0.5$ was taken statistically significant. The simple relationship between PCBs load and milk was studied using analysis of variance while the analysis of covariance (ANOVA) was applied in order to adjust for confounders. The analyses were carried out using the SAS software (version 9.1; SAS Institute Inc., Cary, NC, USA).

\section{RESULTS}

The detection of PCB congeners in all the samples analyzed indicates the spatial distribution in Karachi women. Multiparous women were found to have more PCB concentration than primiparaous women. The results indicated the remarkable difference between the two groups of women. PCB 28 was entirely absent in primiparous women on the other hand PCB 138 was not detected in any of the milk samples from multiparaous women. By looking into the individual concentration of each PCB the primiparous milk samples were found to have the concentration of PCB congeners as N.A, $0.058 \mathrm{ng} / \mathrm{ml}$, $0.017 \mathrm{ng} / \mathrm{ml}, 0.006,0.008 \mathrm{ng} / \mathrm{ml}, 0.083 \mathrm{ng} / \mathrm{ml}$ and N.A for PCB 28, 52, 101, 138, 153, 180 and 209 respectively (Table 1). On the other hand mean values for the same PCB congeners in multiparous milk samples were detected as $0.006 \mathrm{ng} / \mathrm{ml}, 0.025 \mathrm{ng} / \mathrm{ml}, 0.001 \mathrm{ng} / \mathrm{ml}$, N.A, $0.003 \mathrm{ng} / \mathrm{ml}, 0.244 \mathrm{ng} / \mathrm{ml}$ and $0.166 \mathrm{ng} / \mathrm{ml}$ (Table 2).

The sum of mean values i.e., $\Sigma$ PCB in multiparous women was found to be $0.445 \mathrm{ng} / \mathrm{ml}$ where as the $\Sigma$ PCB in primiparous women samples was $0.172 \mathrm{ng} / \mathrm{ml}$. The one PCB congener i.e. PCB 209 make the difference as this $\mathrm{PCB}$ concentration was entirely absent in primipara samples whereas it was detected in the highest concentration in multiparaous women milk samples as 0.166 $\mathrm{ng} / \mathrm{ml}$.

\section{DISCUSSION}

To best of our knowledge this study was the first to elucidate the concentration status of PCB congeners in women subject of Karachi. From the standpoint of Asian countries the reports are available from Philippines [14] and Japan [15].

According to [14] polychlorinated diphenyl ethers and hexabromocyclododecanes had no significant relationship between primiparous and multiparous women with reference to its status of concentration. They have covered a range of POPs accumulation in breast milk of women in addition to PCB congeners. The primiparous mothers had significantly higher organochlorinated insecticides such as DDTs, CHLs and HCHs than multiparous women and no such trend was reported with reference to PCB congeners determined a range of PCBs in blood and milk samples of mothers [16]. They reported the mean levels of many PCB congeners as 7.1, 2.7, 5.3 and $0.4 \mathrm{pg}$ in primiparous mothers. The present investigation concerning with the milk samples only as the multiparous women samples were found to have mean values as $0.445 \mathrm{ng} / \mathrm{ml}$ ( $\Sigma$ PCB) and primiparous women milk samples indicated $\Sigma$ PCB value as $0.172 \mathrm{ng} / \mathrm{ml}$. Our investigation indicate that multiparous women remain at high risk of PCB transfer from their breast milk to the infants than primiparous women was based on findings from 30 mothers which includes 15 primiparous and 15 multiparous mothers (Figure 1).

It is known that the level of PCB congeners reflects the mother's exposure to these chemicals during their life time. Mean concentrations of the sum of PCBs in the analyzed milk samples seems to be relatively low as $114.8 \mathrm{ng} / \mathrm{g}$ in primipara and $101.8 \mathrm{ng} / \mathrm{g}$ in secundipara [17]. Mean concentration of these chemicals shows an incline trend of the persistent organic pollutants in multiparaous women residing in Karachi since the time when chemicals like PCB were ban and restricted.

The concentrations of the PCBs [138, 153 and 180] in first-time pregnant female and multiparous women reported to be higher than those for pregnant serum females. A research report conducted by showed the PCB congeners in women in the following order as PCB 138 $(11.2 \mathrm{ng} / \mathrm{g})$, PCB $153(14.7 \mathrm{ng} / \mathrm{g})$ and PCB $180(8.3 \mathrm{ng} / \mathrm{g})$ for primiparous women and PCB $138(6.1 \mathrm{ng} / \mathrm{g})$, PCB $153(5.3 \mathrm{ng} / \mathrm{g})$ and PCB $180(4.5 \mathrm{ng} / \mathrm{g})$ for multiparaous women [18].

The previous results clearly indicate that PCB-153 was higher than PCB-28 in primiparous [19] same as present investigation.

Present results indicate that residues of PCBs in breast milk of women do not reliably decrease over the number of child or course of lactation. This is contrast with a more recent study on depuration of PCBs in milk [20].

It could be assumed from the above results that in the developed countries rate of persistency of POP's are relatively reduced in human biological materials which may be due to the awareness of hazardous effects of PCBs or strict implementation of law in terms of use of such banned chemicals.

Present investigation shows that human milk samples were highly contaminated with PCBs. Their concentration was found to be comparatively higher than previous finding. The use of such industrial chemicals should be strictly monitored, as their deposition may increase the environmental contamination. The disposal of PCB con- 
Table 1. Statistical analysis of PCB residues ( $\mathrm{ng} / \mathrm{ml})$ in milk samples of primipara women.

\begin{tabular}{ccccccc}
\hline Name of PCBs & Positive samples & Positive test (\%) & Mean & SD & SE & Range min - mix \\
\hline PCB 28 & 00 & 00 & 00 & 00 & 00 & 00 \\
PCB 52 & 5 & 33 & 0.058 & 0.236 & 0.063 & $0.484-11.507$ \\
PCB 101 & 5 & 33 & 0.017 & 0.128 & 0.034 & $1.599-4.943$ \\
PCB 138 & 2 & 13 & 0.006 & 0.077 & 0.020 & $1.387-2.530$ \\
PCB 153 & 5 & 33 & 0.008 & 0.089 & 0.023 & $1.516-3.036$ \\
PCB 180 & 6 & 40 & 0.083 & 0.0213 & 0.057 & $2.464-3.306$ \\
PCB 209 & 00 & 00 & 00 & 00 & 00 & 00 \\
$\mathbf{\Sigma}$ PCB & & & $\mathbf{0 . 1 7 2}$ & & & \\
\hline
\end{tabular}

Table 2. Statistical analysis of PCB residues $(\mathrm{ng} / \mathrm{ml})$ in milk samples of multipara women.

\begin{tabular}{ccccccc}
\hline Name of PCBs & Positive samples & Positive test (\%) & Mean & SD & SE & Range min - mix \\
\hline PCB 28 & 4 & 27 & 0.006 & 0.081 & 0.021 & $1.425-2.565$ \\
PCB 52 & 7 & 46 & 0.025 & 0.157 & 0.040 & $1.425-6.175$ \\
PCB 101 & 4 & 27 & 0.001 & 0.041 & 0.010 & $0.855-1.045$ \\
PCB 138 & 00 & 00 & 00 & 00 & 00 & 00 \\
PCB 153 & 4 & 27 & 0.003 & 0.059 & 0.015 & $1.140-1.710$ \\
PCB 180 & 9 & 60 & 0.244 & 0.219 & 0.056 & $17.86-28.50$ \\
PCB 209 & 4 & 27 & 0.166 & 0.328 & 0.084 & $7.790-23.75$ \\
$\mathbf{\Sigma}$ PCB & & & $\mathbf{0 . 4 4 5}$ & & & \\
\hline
\end{tabular}

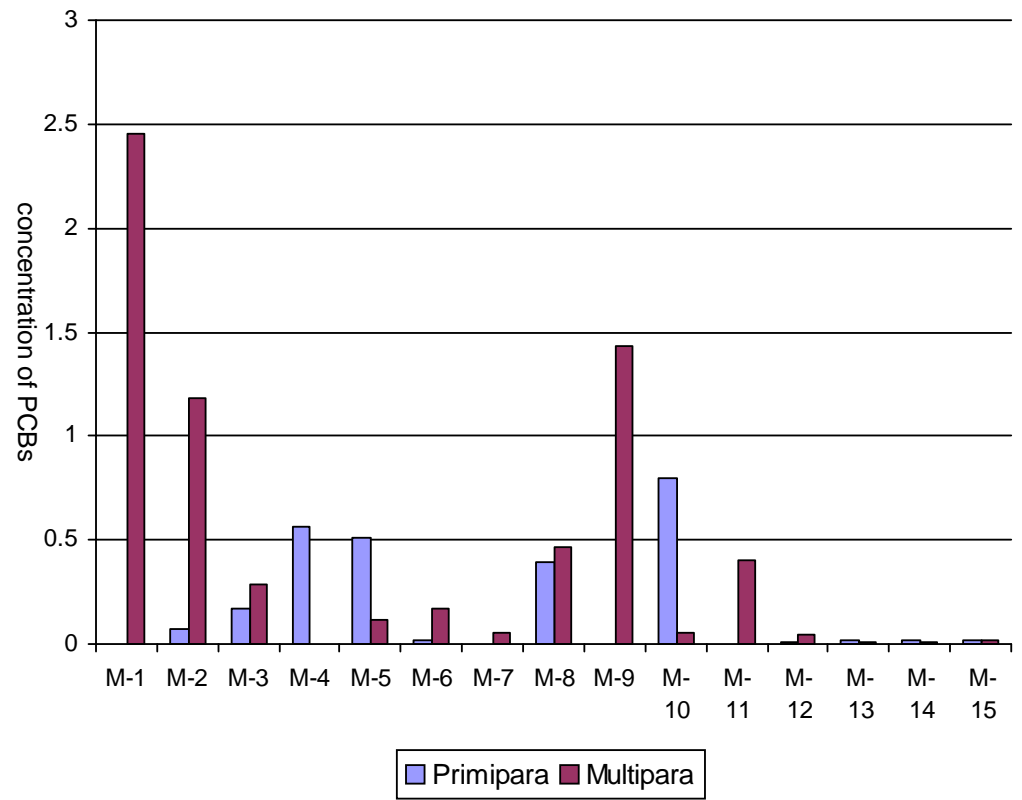

Figure 1. Bar graph showing total PCB concentration in 15 primipara and 15 multipara.

centration as a waste product from some industries may increase the risk of its entry in human body.

In the city of Karachi there are large area used as a waste source. Municipal wastes are burned under low temperature. It leads to the formation of PCBs under low temperature. The pollution near the wastage sites are likely to be more infected with the PCB concentrations as compared to those living away from such sites. Further, the PCBs come from electric appliances like tube lights and also in materials like carbon paper and plastic products which were dumped in considerable quantities daily. 
It can be anticipated that if the same situation/condition continues in future then the pollution may rise more and hence the concentration levels in human biological materials may also high because the release of these contaminants are not at all controlled even now.

\section{CONCLUSION}

Our PCB contamination is a public health crisis which has been ignored far too long. All samples were found to be contaminated with PCB residues which are no longer used in Pakistan.

\section{REFERENCES}

[1] Hooper, K., She, J.W., Sharp, M., Chow, J., Jewell, N., Gephart, R. and Holden, A. (2007) Depuration of polybrominated diphenyl ethers (PBDEs) and polychlorinated biphenyls (PCBs) in breast milk from California firsttime mothers (primiparae). Environmental Health Perspectives, 115, 1271-1275. http://dx.doi.org/10.1289/ehp.10166

[2] Dallaire, F., Dewailly, E., Muckle, G., Vezina, C., Jacobson, S.W., Jacobson, J.L. and Ayotte, P. (2004). Acute infections and environmental exposure to organochlorines in Inuit infants from Nunavik. Environmental Health Perspectives, 112, 1359-1365. http://dx.doi.org/10.1289/ehp.7255

[3] Shea, J.W., Holdena, A., Sharpa, M., Tannera, M., Williams-Derryb, C. and Hoopera, K. (2007) Polybrominated diphenyl ethers (PBDEs) and polychlorinated biphenyls (PCBs) in breast milk from the Pacific Northwest. Chemosphere, 67, S307-S317.

http://dx.doi.org/10.1016/j.chemosphere.2006.05.154

[4] Rogan, W.J., et al. (1988) Congenital poisoning by polychlorinated biphenyls and their contaminants in Taiwan. Science, 241, 334-336. http://dx.doi.org/10.1126/science.3133768

[5] Law, D.C., Klebanoff, M.A., Brock, J.W., Dunson, D.B. and Longnecker, M.P. (2005) Maternal serum levels of polychlorinated biphenyls and 1,1-dichloro-2,2-bis(p-chlorophenyl)ethylene (DDE) and time to pregnancy. American Journal of Epidemiology, 162, 523-532. http://dx.doi.org/10.1093/aje/kwi240

[6] Longnecker, M.P., Wolff, M., Gladen, B.C., Brock, J.W., Grandjean, P., Jacobson, J.L., Korrick, S.A., Rogan, W.J., Weisglas-Kuperas, N., Hertz-Piccioto, I., Ayotte, P., Stewart, P., Winneke, G., Charles, M.J., Jacobson, S.W., Dewailly, E., Boersma, E.R., Altshul, L.M., Heinzow, B., Pagano, J.J. and Jensen, A.A. (2003) Comparison of polychlorinated biphenyl (PCB) levels across studies of human neurodevelopment. Environmental Health Perspectives, 111, 65-70. http://dx.doi.org/10.1289/ehp.5463

[7] Petrik, J., Drobna, B., Pavuk, M., Jursa, S., Wimmerova, S. and Chovancova, J. (2006) Serum PCBs and organochlorine pesticides in Slovakia: Age, gender, and residence as determinants of organochlorine concentrations. Chemosphere, 65, 410-425. http://dx.doi.org/10.1016/j.chemosphere.2006.02.002
[8] Korrick, S.A. and Altshul, L. (1998) High breast milk levels of polychlorinated biphenyls (PCBs) among four women living adjacent to a pcb-contaminated waste site. Environmental Health Perspectives, 106, 513. http://dx.doi.org/10.1289/ehp.98106513

[9] Schwacke, L.H., Voit, E.O., Hansen, L.J., Wells, R.S., Mitchum, G.B., Hohn, A.A. and Fair, P.A. (2002) Probabilistic risk assessment of reproductive effects of polychlorinated biphenyls on bottlenose dolphins (tursiops truncatus) from the southeast United States Coast. Environmental Toxicology and Chemistry, 21, 2752-2764.

[10] Ataniyazova, O.A., Baumann, R.A., Liem, A.K., Mukhopadhyay, U.A., Vogelaar, E.F. and Boersma, E.R. (2001) Levels of certain metals, organochlorine pesticides and dioxins in cord blood, maternal, blood, human milk and some commonly used nutrients in the surroundings of the Aral Sea (Karakalpakstan, Republic of Uzebkistan). Acta Paediatrica, 90, 801-808. http://dx.doi.org/10.1111/j.1651-2227.2001.tb02808.x

[11] Covaci, A., Jorens, Ph., Jacquemyn, Y. and Schepens, P. (2002) Distribution of PCB and organochlorine pesticides in umbilical cord and maternal serum. Science of the Total Environment, 298, 45-53. http://dx.doi.org/10.1016/S0048-9697(02)00167-5

[12] Yao, Y., Takasuga, T., Masunaga, S. and Nakanishi, J. (2002) Detailed study on the levels of polychlorinated dibenzo-p-dioxins, polychlorinated dibenzofurans and polychlorinated biphenyls in Yusho rice oil. Chemosphere, 46, 1461-1469. http://dx.doi.org/10.1016/S0045-6535(01)00254-5

[13] Munshi, A.B., Boardman, G., Flick, G., Cobb, J. and Lane, R. (2008) Pesticides (OCPs) and polychlorinated biphenyls (PCBs) concentration in various fish species along the Chesapeake Bay near Virginia Beach on the Atlantic Coastline. The Open Oceanography Journal, 3, 1-8. http://dx.doi.org/10.2174/1874252100903010001

[14] Malarvannani, G., Kunisue, T., Isobel, T., Sudaryan, A., Takahash, S., Prudente, M. and Tanabe, S. (2008) Spatial spatial distribution and accumulation of organohalogen compounds in human breast milk from the Philippines. Interdisciplinary Studies on Environmental ChemistryBiological Responses to Chemical Pollutants, 339-347.

[15] Todaka, T., Hirakawa, H., Kajiwara, J., Hori, T., Tobish, K., Onozuka, D., Kato, S., Sasaki, S., Nakajima, S., Saijo, Y., Sata, F., Kishi, R., Lida, T. and Furue, M. (2008) Concentration of polychlorinated dibenzo-p-dioxins, polychlorinated dibenzofurans and dioxin-like polychlorinated biphenyls in blood and breast milk collected from 60 mothers in Sapporo City. Japan.

[16] Lignell, S., Darnerud, P.O., Aune, M. and Törnkvist, A. (2004) Report to the Swedish Environmental Protection Agency, 2004-06-01. Polychlorinated biphenyls and chlorinated pesticdes/metabolites in breast milk from primiparae women in Uppsala County, Sweden-Levels and Trends 1996-2003, 1-15.

[17] Szyrwinska, K. and Lulek, J. (2007) Exposure to specific polychlorinated biphenyls and some chlorinated pesticides via breast milk in Poland. Chemosphere, 66, 18951903. http://dx.doi.org/10.1016/j.chemosphere.2006.08.010 
[18] Richard, Y.W., Ram, B.J., Amy, F.W., Carol, H.R. and Larry, L.N. (2009) Serum concentrations of selected persistent organic pollutants in a sample of pregnant females and changes in their concentrations during gestation. Environmental Health Perspectives, 117, 1244-1249.

[19] Darnerud, P.O., Lignell, S., Atuma, S., Aune, M., Cnattingius, S. and Glynn, A. (2004) Levels and trends of PCB 153 and DDE in breast milk from primiparae women in Uppsala country Sweden. Organohalogen Com-

\section{LIST OF ABBREVIATIONS}

PCB: polychlorinated biphenyls

SD: standard deviation deviation

GC: gas chromatograph

pg: picogram pound, 66, 2884-2890.

[20] Hooper, K., She, J., Sharp, M., Chow, J., Jewell, N., Gephart, R. and Holden, A. (2007) Depuration of polybrominated diphenyl ethers (PBDEs) and polychlorinated biphenyls (PCBs) in breast milk from California firsttime mothers (primiparae). Environmental Health Perspectives, 115, 1271-1275.

http://dx.doi.org/10.1289/ehp.10166

ml: milliliter

ng: nonogram

LOQ: limit of quantitation

ECD: electron capture detector 